\title{
A produção mais limpa como ferramenta da sustentabilidade empresarial: um estudo no estado do Rio Grande do Norte
}

\author{
Handson Claudio Dias Pimenta* ${ }^{\mathrm{a} *}$, Reidson Pereira Gouvinhas ${ }^{\mathrm{b}}$ \\ a*handson.pimenta@ifrn.edu.br, IFRN, Brasil \\ breidson@ct.ufrn.br, UFRN, Brasil
}

\begin{abstract}
Resumo
0 presente estudo teve como objetivo avaliar a produção mais limpa - PmL como ferramenta da sustentabilidade empresarial através de uma série de estudos de múltiplos casos em empresas do estado do Rio Grande do Norte. Para tanto, foi aplicada a metodologia de PmL modelo SEBRAE (2005) em três empresas: uma indústria de alimentos (empresa 1), uma indústria de confecções (empresa 2) e uma concessionária de veículos (empresa 3). Pelos resultados, destacam-se, na empresa 1, ações de substituição de matéria-prima, otimização do uso de água e energia. Na empresa 2, otimização do uso de tecido e modificação tecnológica. Por fim, na empresa 3, as medidas de segregação na fonte e reciclagem externa de resíduos. Contudo, foram evidenciadas melhorias nas vertentes ambiental, social e econômica, preconizadas pela sustentabilidade empresarial. Entretanto, faz-se necessário mais transparência da alta administração no comprometimento com a continuidade das ações para, diante disto, melhor enquadrar a PmL como uma ferramenta da sustentabilidade.
\end{abstract}

Palavras-chave

Sustentabilidade empresarial. Produção mais limpa. Competitividade. Impactos ambientais. Desperdício.

\section{Introdução}

A inclusão do conceito desenvolvimento sustentável no mundo corporativo foi definida pelo World Business Council for Sustainable Development (WBCSD) como o alcance do equilíbrio entre as três dimensões que balizam a sustentabilidade corporativa: a econômica; a ambiental e a social, as quais influenciam todas as organizações constituintes das cadeias produtivas.

Assim, nota-se que o desenvolvimento sustentável requer que o setor empresarial adote uma política de proteção socioambiental consonante ao desenvolvimento econômico. Nesse contexto, as empresas são capazes de realizar mudanças fundamentais em novos objetivos, para aumentar a qualidade enquanto diminuem os custos (PEREIRA, 2003). Além do exposto, evitando as penalidades da lei e as pesadas multas decorrentes do descumprimento da legislação, o empresário também deseja reforçar a condição de empresa social e ambientalmente correta e responsável, uma vantagem competitiva diante do mercado globalizado.
Destacam-se como indutores da necessidade da implementação de ferramentas que buscam a sustentabilidade empresarial os elementos do governo (legislação ambiental e políticas de controle), a competição do mercado (concorrentes, investidores e consumidores) e a responsabilidade socioambiental. Logo, a ferramenta da produção mais limpa (PmL) pode ser implementada, respondendo a essas pressões, uma vez que pode reduzir o risco das operações sobre 0 meio ambiente e a sociedade, bem como estimulando as empresas a se autoavaliarem continuamente.

Diante deste cenário, a PmL, que tem como finalidade aprimorar a eficiência dos processos produtivos e serviços, é apontada como um caminho favorável de atuação das empresas, de forma preventiva em relação aos seus aspectos ambientais e na redução dos riscos das operações aos funcionários e à comunidade, logo, na busca da sustentabilidade.

Entretanto, o que se percebe é que ainda há pouco debate sobre as práticas empresariais que contemplam 
a busca da sustentabilidade, incluindo estudos mais aprofundados sobre a produção mais limpa. Isso porque ainda existem diversas barreiras e limitações quanto à sua adequada implementação, o que se reflete na necessidade do contínuo aprimoramento desta ferramenta.

Sendo assim, o presente trabalho tenta responder, a partir de um estudo de múltiplos casos em empresas do estado do Rio Grande do Norte, às seguintes questões-problema: quais são os benefícios ambientais, sociais e financeiros da implementação da PmL nos casos estudados?

A partir dessa indagação, o objetivo geral do presente é avaliar a implementação da produção mais limpa como ferramenta da sustentabilidade empresarial no estado do RN através de uma série de estudos de múltiplos casos em empresas do setor alimentício, do setor têxtil e de serviços. Especificamente, a pesquisa busca fornecer elementos de discussão para que cada empresa estudada passe a identificar e a incorporar a variável ambiental no seu processo de gestão corporativa.

\section{Revisão da literatura}

\subsection{O desenvolvimento sustentável e as empresas}

0 termo desenvolvimento sustentável - DS foi lançado em abril de 1987. O conceito de desenvolvimento sustentável foi apresentado pela World Commission on Environmental Development, um organismo independente, vinculado aos governos e ao sistema das Nações Unidas, durante a Assembleia Geral das Nações Unidas, através do Relatório Brundtland, como sendo: "o desenvolvimento que atende as necessidades do presente sem comprometer a habilidade das futuras gerações de encontrar suas próprias necessidades." (UNITED NATIONS, 1987).

Para Robles Junior e Boneli (2006), na definição estabelecida pelo Relatório Brundtland estão inseridos dois conceitos: o primeiro, das necessidades, que podem variar de sociedade para sociedade, mas que devem ser satisfeitas para assegurar as condições essenciais de vida a todos, indistintamente. 0 segundo conceito é o da limitação, que reconhece a necessidade de a tecnologia desenvolver soluções que conservem os recursos limitados atualmente disponíveis e que permitam renová-los, na medida em que eles são necessários às futuras gerações.

Em adição, The Center for Applied Policy Research afirma que o DS pressupõe a manutenção do crescimento econômico enquanto gera o mínimo absoluto de poluentes, reparando os danos ambientais do passado, usando menos recursos não renováveis, produzindo menos desperdício, além de entender o valor de viver em uma ambiente agradável e saudável para toda a população (CENTRE..., 2003).

Não diferentemente da abordagem genérica observada anteriormente, a inclusão do conceito de desenvolvimento sustentável no mundo corporativo foi definida pelo World Business Council for Sustainable Development como o alcance do equilíbrio entre os três domínios ou dimensões que balizam a sustentabilidade - a econômica; a ambiental e a social.

Almeida (2002) considera que uma organização sustentável é aquela que busca a ecoeficiência em todas as suas ações e decisões, em todos os seus processos e produtos, incessante e permanentemente, ou seja, busca produzir mais e melhor com menos, mais produtos de melhor qualidade, com menos poluição e menos uso dos recursos naturais e com responsabilidade social.

Coral (2002) assegura que para uma empresa ser considerada sustentável é necessário que ela atenda os critérios de ser economicamente viável, ocupar uma posição competitiva no mercado, produzir de forma que não agrida o meio ambiente e contribuir para 0 desenvolvimento social da região e do país onde atua.

Em adição, Cramer e Stevels (2001) afirmam que um negócio sustentável permite uma redução de custos, fortalece a posição no mercado, cria novos mercados e evita críticas de stakeholders externos, além de aumentar a possibilidade de sobrevivência das empresas a longo prazo.

Nessa linha, Hart e Milstein (2004, p. 68) consideram que

[...] o desenvolvimento sustentável desafia as empresas a funcionarem de uma maneira transparente, responsável, tendo em vista a existência de uma bem informada e ativa base de stakeholders.

Assim, Kuhndt (2004) afirma que a política e a estratégia empresarial, junto com o processo de tomada de decisão, precisam ser integradas aos aspectos econômicos, sociais e ambientais. Para tanto, o autor apresenta medidas aplicáveis ao dia a dia dos negócios, para seus diferentes níveis corporativos (estratégico, tático e operacional).

0 nível estratégico comporta a visão macro da empresa no que diz respeito à questão da sustentabilidade, ou seja, a empresa deve se posicionar no mercado de tal modo que expresse a forma que a sustentabilidade influenciará as suas decisões de negócio. No nível tático, a empresa começa a definir o conjunto de produtos e serviços que deverão ser ofertados ao mercado em consonância com a visão estratégica. A seguir, no operacional, mecanismos/ferramentas são definidos para colocar 
em prática todo o portfólio de produtos e serviços definidos a nível tático. Contudo, as transformações de decisões nestes três níveis devem acontecer de forma suave e natural, de tal forma que a questão da sustentabilidade possa permear toda a empresa (KUHNDT, 2004).

Em adição, alguns mecanismos gerencias e operacionais são sugeridos na literatura. Por exemplo, Jappur (2004) recomenda: para que uma organização avance na direção da sustentabilidade ela deve adotar alguns métodos que as ajudem nesta condução, a saber: responsabilidade social corporativa; governança corporativa; ecoeficiência; análise do ciclo de vida; emissão zero; sistemas de gestão certificáveis; produção mais limpa e relatórios de sustentabilidade corporativa. Para o autor, a aplicação de um método não impossibilita a utilização concomitante de outros.

Destaca-se ainda no estudo de Jappur a indicação da produção mais limpa, objeto deste estudo, como ferramenta da sustentabilidade. A referida ferramenta também é citada pelo Philippine Council for Sustainable Development (2008), que sugere que a PmL está inserida entre duas dimensões da sustentabilidade - economia e natureza (ambiental).

Ressalta-se também que PmL é um conceito de melhoria contínua que permite aperfeiçoar a eficiência, a lucratividade e a competitividade das empresas, enquanto protege o meio ambiente, o consumidor e o trabalhador (ALMEIDA; GIANNETTI, 2006).

Não obstante, as iniciativas empresariais, como a simples adoção de uma ou outra ferramenta ou mecanismo não significa que a empresa alcançou a sua plenitude no que diz respeito à sustentabilidade empresarial. Cada iniciativa implementada deve ser encarada como um processo de aprendizado contínuo.

\subsection{Produção mais limpa: uma ferramenta da sustentabilidade empresarial}

\subsubsection{Breve histórico da PmL}

Em 1994, a United Nations Industrial Development Organization - UNIDO e o United Nations Environment Programme - UNEP iniciaram juntamente o programa mundial dos centros de produção mais limpa, com o objetivo de promover, coordenar e facilitar as atividades da PmL em cada país, através da construção da capacidade local de implementar a PmL e formar profissionais que pudessem aplicar os conceitos ou mesmo ajustá-los às condições locais (UNITED..., 2002, 2007)

Um total de 25 centros foi estabelecido desde 1995, nos seguintes países: Brasil, China, Costa Rica, República Checa, El Salvador, Etiópia, Guatemala,
Hungria, Coreia, Líbano, México, Marrocos, Moçambique, Nicarágua, República Eslovaca, África do Sul, Tanzânia, Tunísia, Uganda, Vietnam e Zimbábue. Segundo Luken e Navratil (2007), foram investidos mais de 17 milhões de dólares para formação dos centros, com um retorno de 4 milhões anuais.

No Brasil, o centro, denominado Centro Nacional de Tecnologias Limpas - CNTL, foi instalado em julho de 1995 no Serviço Nacional de Aprendizagem Industrial (Senai) do Rio Grande do Sul (CENTRO..., 2003). Em 1999 foi implementada a Rede Brasileira de Produção Mais Limpa, com o intuito de promover o desenvolvimento sustentável nas micro e pequenas empresas brasileiras. Atualmente, a rede é formada por sete núcleos estaduais (MG, BA, SC, MT, RJ, CE e PE) e onze núcleos regionais do SEBRAE (DF, AM, AP, MS, $\mathrm{PA}, \mathrm{ES}, \mathrm{AL}, \mathrm{RJ}, \mathrm{RN}, \mathrm{Pl}$ e SE). Essa rede completou uma década de atuação no Brasil e implementou a PmL em mais de 300 empresas, proporcionando melhorias no desempenho ambiental e ganhos econômicos.

No Rio Grande do Norte, o CNTL/Senai-RN, em 2003, em parceria com o SEBRAE-RN, formou a primeira turma de consultores em PmL. 0 resultado final culminou na aplicação da metodologia em seis empresas do estado. De acordo com dados do Núcleo Potiguar de Econegócios, nessas seis empresas os investimentos necessários para implementação do programa foram pouco mais de $\mathrm{R} \$ 21$ mil e o retorno ultrapassou R\$ 150 mil em um ano. Os benefícios ambientais traduzem-se em otimização do uso de materiais, redução do consumo de água e minimização do risco de contaminação (SEBRAE-RN, 2005).

\subsubsection{Conceitos, níveis de oportunidade e barreiras da produção mais limpa}

De acordo com a UNIDO (UNITED..., 2002), a PmL consiste em uma estratégia preventiva e integrativa, que é aplicada a todo ciclo de produção para: a) aumentar a produtividade, assegurando um uso mais eficiente de matéria-prima, energia e água; b) promover melhor desempenho ambiental, através da redução de fontes de desperdícios e emissão; c) reduzir o impacto ambiental por todo o ciclo de vida de produtopor meio de um desenho ambiental com baixo custo efetivo.

Já a UNEP complementa que a PmL é uma estratégia ambiental que auxilia a organização a aumentar a eficiência global e reduzir os riscos aos seres humanos e ao meio ambiente.

A PmL pode ser adotada em qualquer setor e porte de atividade a partir de uma análise técnica, econômica e ambiental detalhada do processo produtivo, objetivando a identificação de oportunidades que possibilitem melhorar a eficiência, sem acréscimo 
de custos para a empresa (WEIHS; WEISSEL, 2005; SILVA; MEDEIROS, 2006).

Para Glavic e Lukman (2007), a PmL inclui tanto uma condição para atingir melhorias ambientais no processo e desenvolvimento de produtos quanto uma contribuição para uma maior sustentabilidade do mundo.

As oportunidades de melhoria baseadas na PmL podem ser desenvolvidas em três níveis, a saber: nível 1 - redução na fonte; nível 2 - reciclagem interna e nível 3 - reciclagem externa (CENTRO..., 2003; SEBRAE, 2005) (Figura 1). 0 primeiro nível é marcado pela redução na fonte, através de medidas que visam otimizar o uso de recursos e evitar a geração de poluentes, via modificação no produto ou modificação no processo (Housekeeping, mudanças em matérias-primas e modificação tecnológica). Os poluentes que não podem ser evitados devem ser reintegrados ao processo de produção da empresa (reciclagem interna). Somente depois de buscar as soluções de eliminação ou redução na fonte e de reciclagem interna é que se deve optar por medidas de reciclagem de resíduos e efluentes fora da empresa (nível 3) (CENTRO..., 2003; SEBRAE, 2005).

É essencial que no processo de implementação de um programa de PmL as barreiras que surjam sejam superadas. Os maiores obstáculos, além da pouca interação entre a iniciativa privada e as universidades e centros de pesquisas para o desenvolvimento conjunto de ações de PmL, são: resistência à mudança, concepção errônea (falta de informação sobre a técnica e a importância dada ao ambiente natural), a não existência de políticas nacionais que deem suporte às atividades de PmL, barreiras econômicas (alocação incorreta dos custos ambientais e investimentos e baixa capacidade de investimento) e barreiras referentes ao papel da equipe de implantação (ARAÚJO, 2002;
MASERA et al., 2004; SHI; PENG; ZHONG, 2007; STONE, 2006; CAMPOS; RABELO; SANTOS, 2005; CICCOZZI; CHECKENYA; RODRIGUEZ, 2003).

\section{Metodologia}

0 estudo em tela pode ser classificado como uma pesquisa aplicada, com uma abordagem quantitativa e explicativa através de um estudo de casos múltiplos, já que envolveu duas ou mais instituições (SILVA; MENEZES, 2001).

As unidades de análise foram escolhidas com base em critérios como acessibilidade e interesse das empresas em participar do estudo, sendo elas uma indústria de panificação, uma indústria têxtil - confecções e estamparia - e uma concessionária de veículos, agora denominadas, respectivamente, empresa 1, empresa 2 e empresa 3.

\subsection{Descrição dos procedimentos da pesquisa de campo}

Na pesquisa de campo, que ocorreu no período julho/2005 a dezembro/2008, foi utilizado o modelo de aplicação de PmL - SEBRAE (2005). Para simplificar o processo, foram estabelecidas as etapas descritas a seguir (ver Figura 2):

\subsubsection{Planejamento}

$\mathrm{Na}$ fase de planejamento buscou-se, inicialmente, obter comprometimento e envolvimento da gerência, através de uma reunião inicial, na qual foram apresentados a metodologia, as vantagens e alguns casos de sucesso de implementação da PmL.

Também foi definida a equipe interna de implementação do projeto - ecotime, levando em

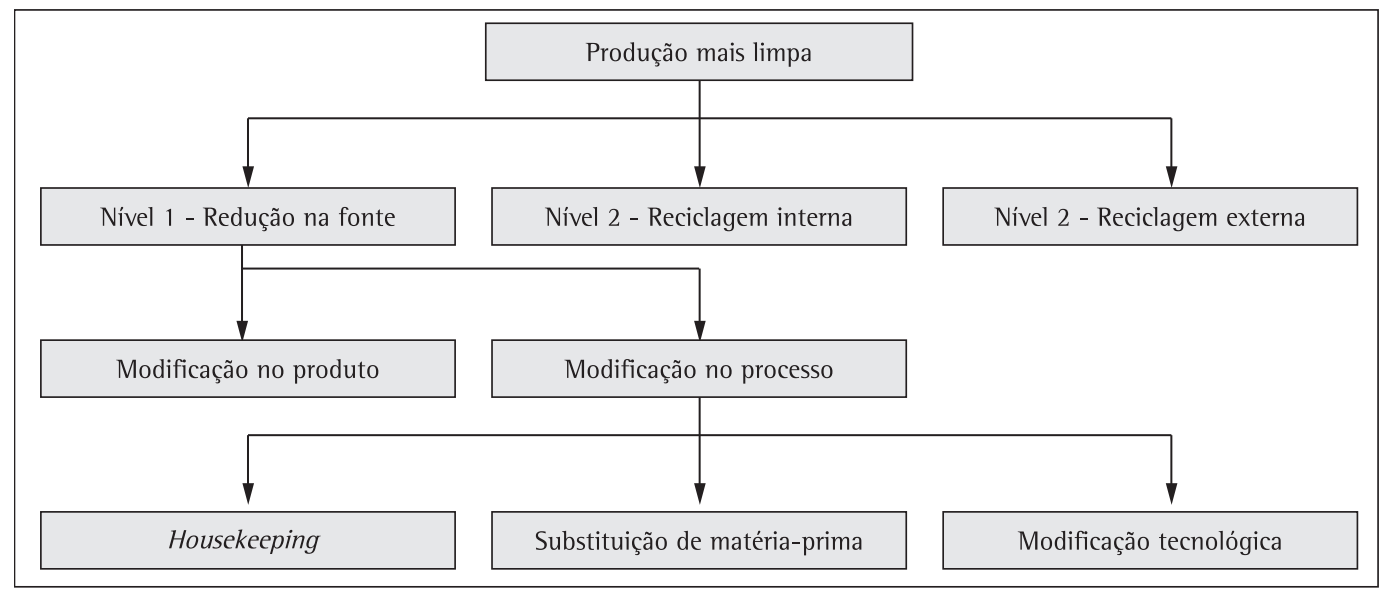

Figura 1. Níveis de oportunidade da produção mais limpa. Fonte: adaptado de Centro Nacional de Tecnologias Limpas (2003) de Tecnologias Limpas (2003). 


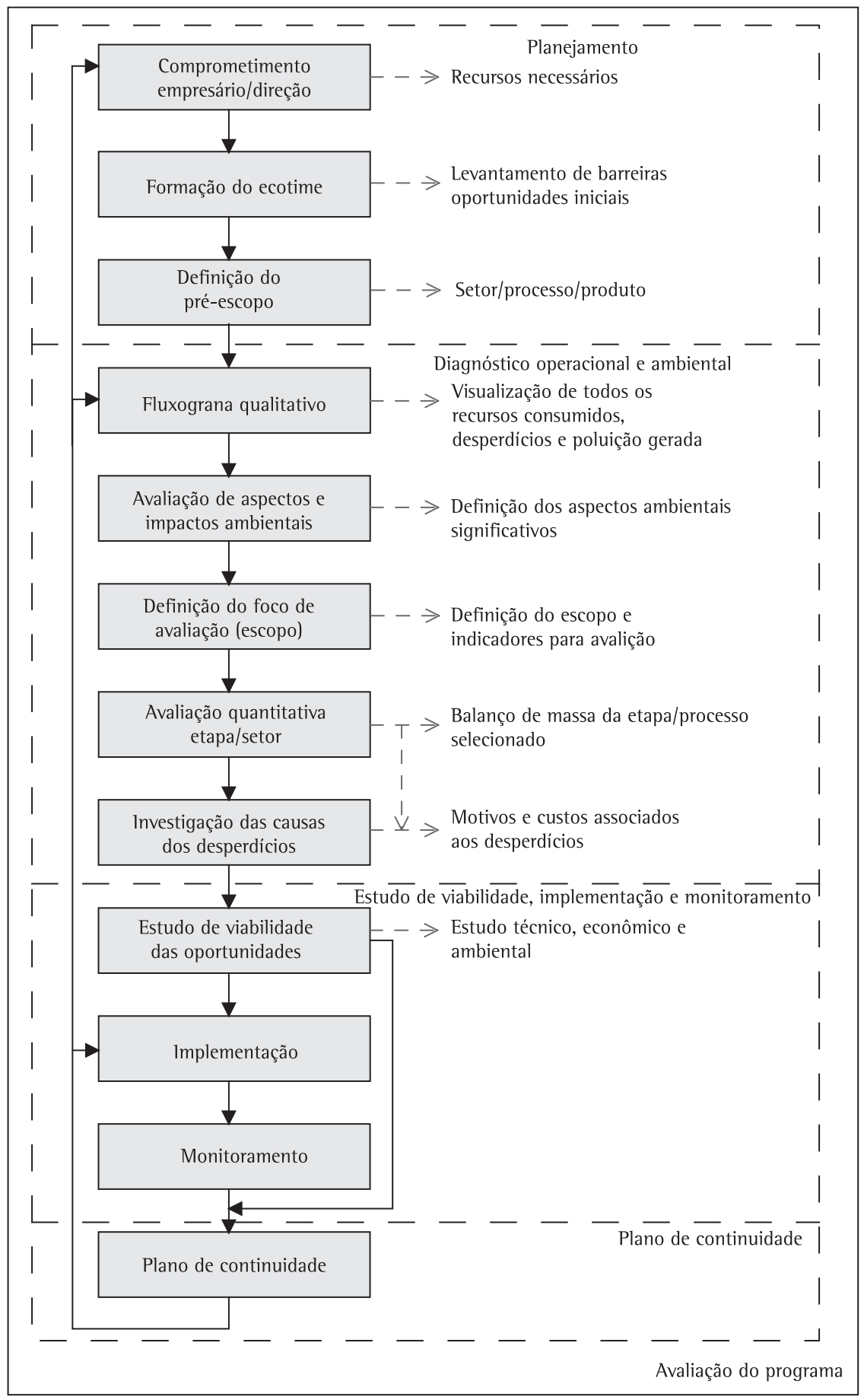

Figura 2. Etapas da pesquisa de campo.

consideração critérios como liderança, conhecimento dos processos, representatividade e uma indicação da alta administração. No processo de capacitação do ecotime foi montado um programa de treinamento de 10 horas contemplando os seguintes temas: qualidade, segurança do trabalho e PmL.
Nessa etapa procurou-se também definir com a gerência e com o ecotime, após um reconhecimento dos produtos, serviços, processos e etapas, um pré-escopo de atuação, isto é, em qual setor/processo poderia ser efetuado o processo de implementação da PmL. 


\subsubsection{Diagnóstico operacional e ambiental}

A segunda etapa consistiu no levantamento das informações de ordem operacional (e.g. equipamentos, materiais, mão de obra, custos associados aos aspectos ambientais etc.) e ambiental (e.g. licença ambiental, existência de programas, procedimentos ou mecanismos de controle ambiental etc.).

Em seguida foi elaborado o fluxograma qualitativo do setor/processo/produto, seguido da avaliação de aspectos e impactos ambientais, seguindo a metodologia do SEBRAE (2005), que visou apontar os aspectos significativos do processo.

Por fim foram escolhidas as etapas/operações/setor que teriam as entradas e saídas quantificadas, a fim de identificar as causas do desperdício e as perdas atribuídas. Para realizar os levantamentos, foram utilizados equipamentos auxiliares como balança, cronômetro, decibelímetro, medidores de tensão elétrica e máquina fotográfica digital.

\subsubsection{Estudo de viabilidade das oportunidades, implementação e monitoramento}

No estudo de levantamento de oportunidades de melhoria, para cada solução foi analisado o grau de impacto da sua implementação frente aos benefícios ambientais e financeiros. Nos benefícios ambientais foram utilizados os indicadores ambientais obtidos no diagnóstico para projetar um cenário da situação encontrada e depois situação proposta ou implementada - com base em estimativas ou no monitoramento.

Os critérios utilizados na análise de viabilidade financeira foram: valor presente líquido - VPL (da situação encontrada e proposta, comparando as alternativas) e pay-back (ou seja, o tempo de retorno do investimento). Também foi utilizado o valor futuro a partir de séries uniformes aplicadas às receitas oriundas do benefício da implementação.

Com base nas informações financeiras e ambientais, as propostas foram apresentadas e, quando autorizadas pelas gerência das empresas, foram implementadas. Destaca-se que as oportunidades de melhoria não implementadas até o momento de intervenção na empresa foram repassadas para um plano de continuidade e que o empresário se comprometia a implementá-las, a médio e longo prazo. Nesse processo, o empresário foi sensibilizado mais uma vez sobre a importância da continuidade do programa.

\section{Resultados e discussões}

\subsection{Descrição geral das empresas estudadas e do planejamento do programa}

A Tabela 1 apresenta informações gerais sobre as empresas estudadas.

$\mathrm{Na}$ empresa 1, o projeto teve início em julho de 2005 e foi finalizado em setembro do mesmo ano. 0 setor apontado pelo empresário para o desenvolvimento das ações foi a panificação, principalmente pelo histórico de desperdício. Além disso, o foco principal do estudo foi na produção do pão francês, em virtude de ser o produto com maior produção.

Já na empresa 2, o projeto teve início em abril de 2007 e foi finalizado em agosto do mesmo ano. Destaca-se que o foco da investigação não foi definido em cima de um único produto, devido à diversidade da cartela da empresa, mas sobre uma análise global do processo.

Finalmente, na empresa 3, o projeto iniciou em setembro de 2007 teve como escopo o uso da PmL no processo de gerenciamento de resíduos sólidos, no intuito de buscar a redução dos resíduos destinados ao aterro sanitário (sendo finalizado em fevereiro de 2008, com monitoramento até o final do ano).

\subsection{Implantação do programa de produção mais limpa}

\subsubsection{Empresa 1}

0 processo de fabricação do pão francês era composto pelas seguintes etapas: separação e pesagem dos ingredientes (conforme receita padrão); mistura (mistura de todos os ingredientes com água em uma batedeira com capacidade de $40 \mathrm{~kg}$ e potência elétrica de $7 \mathrm{cv}$ ); desenvolvimento (uso de cilindro

Tabela 1. Descrição geral das empresas estudadas.

\begin{tabular}{ccccc}
\hline Empresa & Porte & $\begin{array}{c}\text { Ano inicial da } \\
\text { empresa }\end{array}$ & $\begin{array}{c}N^{0} \text { de } \\
\text { funcionários }\end{array}$ & Descrição produtos/serviços \\
\hline 1 & Pequeno & 1998 & 30 & $\begin{array}{l}80 \text { produtos de panificação, pastelaria e confeitaria e uma produção diária de } \\
\text { aproximadamente } 6 \text { mil pães } \\
\text { Camisetas básicas em algodão, poliéster, dry e piquê, com uma capacidade de } \\
\text { produção de } 400 \text { camisas estampadas por dia }\end{array}$ \\
3 & Pequeno & 1995 & 23 & $\begin{array}{l}\text { Comercialização mensal de } 400 \text { carros novos e mais de } 700 \text { mil peças e } \\
\text { acessórios, com um atendimento médio de 3.500 a 4.500 clientes }\end{array}$ \\
\hline
\end{tabular}


mecânico com $6 \mathrm{cv}$ visando um complemento do desenvolvimento do glúten); divisão (divisão, em equipamento de uso manual, da massa processada em quantidades de $50 \mathrm{~g}$, com tamanho e volume iguais); modelagem (definição de formato do pão utilizando equipamento elétrico de $0,37 \mathrm{~kW}$ ); fermentação (em câmaras específicas, com um tempo médio de 4 horas) e forneamento (cozimento da massa em forno elétrico, com quatro câmaras de queima, com $7 \mathrm{cv}$ de potência, cada). Cada fornada leva aproximadamente 15 minutos (Figura 3).

Os pontos críticos observados no processo serão descritos a seguir. 0 consumo de água na batedeira foi o primeiro ponto de investigação, no qual foi constatado que a dosagem era feita de forma aleatória, sem nenhuma mensuração e controle pelo padeiro. Foi observado que o volume de água em relação à farinha era de 47\% (5\% abaixo do recomendado pelo fabricante). Esse fato representa uma perda de produção de 67 pães/dia (anualmente 19.800 pães). Em valores monetários, a perda mensal era de $\mathrm{R} \$ 412,50$.

Em relação à primeira etapa, na separação de ingredientes, foi levantada a possibilidade de se efetuar um teste de produção com a farinha pré-mescla, à qual por recomendação do fabricante, só é preciso adição de água e fermento para a produção do pão francês. 0 empresário autorizou que fossem realizados dois dias de testes de produção com 100\% de farinha do tipo pré-mescla. Com os testes, foi estimada que a geração de resíduos de embalagens de materiais (sacos de ráfia, baldes de manteiga, embalagens plásticas) diminuiria em aproximadamente 35\% (antes 25,3 kg por mês, passaria para $16,5 \mathrm{~kg}$ ).

Quanto ao tempo de separação, pesagem e alimentação da batedeira, foi observada também uma redução de mais de 70\% do tempo (antes, a manipulação de todos os lotes de produção era feita em torno de 15 minutos, que reduziram-se a 4 minutos). Além disso, o custo do quilo de massa pronta de pão francês passou de $\mathrm{R} \$ 1,52$ para $\mathrm{R} \$ 1,46$ com a mudança. Extrapolando este valor para o final do mês, foi observada uma economia de R $\$ 117,00$.

Em relação ao consumo de energia, foi constatada uma discrepância de tempos no uso tanto da batedeira quanto do cilindro, atingindo-se uma diferença de mais de 40\%. Ou seja, para a mesma quantidade de massa processada, em quatro lotes de produção, havia uma diferença de mais de 5 minutos. Enfatiza-se que na produção diária de pão francês eram consumidos, na batedeira e no cilindro, 3,46 kWh.

Frente aos resultados obtidos no diagnóstico operacional e ambiental, as oportunidades vislumbradas serão apresentadas a seguir. Em relação ao consumo de água foi proposta a compra de um balde graduado, visando a padronização das dosagens, e nele foram

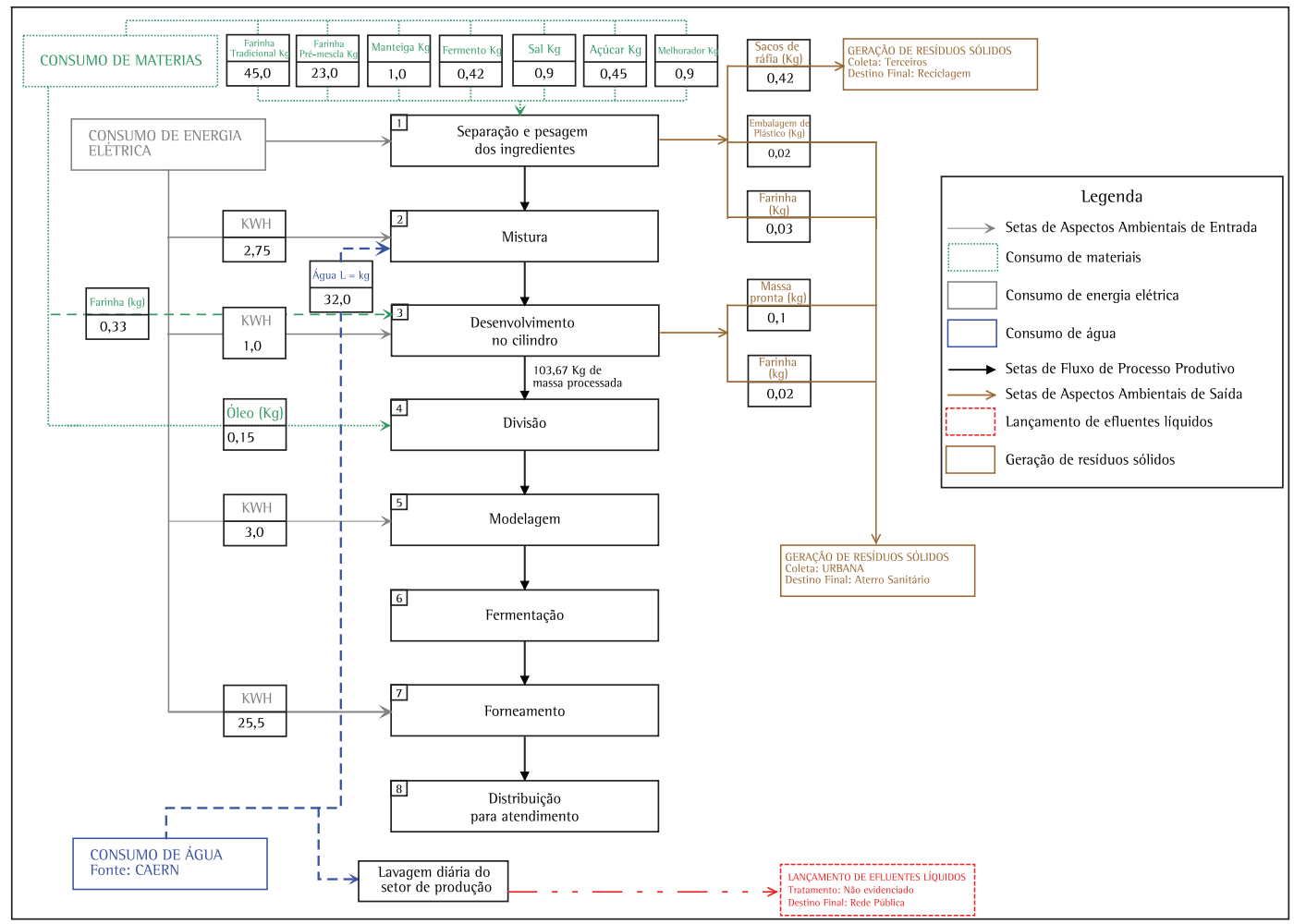

Figura 3. Fluxograma quantitativo empresa 1. 
efetuadas marcações para as dosagem de acordo com os lotes de produção (Nível 1 - Redução na fonte, housekeeping).

Foi também proposto o uso de 100\% de farinha pré-mescla, eliminando os outros ingredientes (sal, açúcar, manteiga e melhorador), facilitando assim o processo produtivo, que passará apenas a manipular: farinha, fermento e água (Nivel 1 - Redução na fonte, substituição de matéria-prima).

Em relação ao controle energético, foram fixados cartazes na batedeira e no cilindro, mostrando o tempo padrão para os respectivos lotes: para $5 \mathrm{~kg}$ de massa (na batedeira, 3,5 minutos, e no cilindro, 2,0 minutos) e para $15 \mathrm{~kg}$ (na batedeira, 5 minutos, e no cilindro, 2,5 minutos) (Nível 1 - Redução na fonte, housekeeping). Assim, foi estimado que o consumo reduziria para $2,68 \mathrm{kWh}$, uma economia anual de $277 \mathrm{kWh}(22 \%)$.

Todas as propostas referentes à produção do pão francês foram acatadas pelo empresário, sendo implementadas de imediato.

Pelos resultados, nota-se que a intervenção feita em cima dos aspectos ambientais significativos da produção do pão francês levou a uma economia total de aproximadamente $\mathrm{R} \$ 7.349,51$ por ano, com baixos valores de investimento e um período de recuperação inferior a um mês (Tabela 2). Analisando o VPL da situação encontrada, observa-se que os desperdícios encontrados, no horizonte de um ano, representavam um custo de R\$ 6.522,31 para a empresa.

Percebe-se com a implementação das oportunidades uma redução de 34\% nos resíduos de embalagens, de 73\% no tempo de manipulação dos ingredientes e de $22 \%$ no consumo de energia elétrica nas etapas de mistura e desenvolvimento. Destaca-se também uma redução de $45 \%$ do custo da massa do pão francês (Tabela 3).

0 plano de continuidade traçado para a empresa 1 consistiu na implementação do programa de coleta seletiva. Também foi especificado que o ecotime passasse a orientar os outros setores na busca do uso eficiente dos ingredientes, através de visitas quinzenais aos outros setores e de reuniões mensais com todos os funcionários.

Após seis meses do programa implantado, a empresa foi visitada, sendo observados os seguintes fatos: o uso da farinha pré-mescla foi extrapolado para outras massas (doce e semidoce); o programa de coleta seletiva não foi implementado na sua totalidade, apenas a venda de baldes e sacos de ráfia; a empresa passou a apoiar eventos na área ambiental: na semana do meio ambiente, passou a distribuir sementes da espécie Saboneteira aos clientes; e todos os resultados da redução de desperdício foram amplamente divulgados para a Associação dos Panificadores de Natal, em reuniões de assembleia e jornal.

\subsubsection{Empresa 2}

0 processo de confecção da Empresa 2 apresentava sete etapas principais (Figura 4). A primeira etapa consiste no design do produto, passando pela modelagem (molde de papelão para cada componente do produto). Em sequência, ocorre o processamento

Tabela 2. Análise de viabilidade das oportunidades na empresa 1.

\begin{tabular}{|c|c|c|c|c|c|c|c|}
\hline \multirow[b]{2}{*}{ Aspecto crítico } & \multirow[b]{2}{*}{ Solução } & \multirow{2}{*}{$\begin{array}{l}\text { Investimento } \\
\text { (R\$) }\end{array}$} & \multicolumn{2}{|c|}{$\begin{array}{c}\text { Receita } \\
\text { gerada/projetada }\end{array}$} & \multicolumn{3}{|c|}{ Análise financeira } \\
\hline & & & Mês (R\$) & $\begin{array}{l}\text { Ano (VF) } \\
\text { (R\$) }\end{array}$ & $\begin{array}{c}\text { VPL } \\
\text { encontrada } \\
(R \$)\end{array}$ & $\begin{array}{l}\text { VPL } \\
\text { proposta } \\
\text { (R\$) }\end{array}$ & $\begin{array}{l}\text { Pay-back } \\
\text { (meses) }\end{array}$ \\
\hline Uso incorreto da água & $\begin{array}{l}\text { Compra de balde e } \\
\text { treinamento }\end{array}$ & 155,00 & 412,50 & $5.231,53$ & $-4.642,72$ & $+4.487,72$ & 0,37 \\
\hline Substituição da farinha & $\begin{array}{c}\text { Uso de } 100 \% \text { de farinha } \\
\text { pré-mescla }\end{array}$ & 0,00 & 117,00 & $1.483,85$ & $-1.316,84$ & $+1.316,84$ & 0,00 \\
\hline $\begin{array}{l}\text { Orientações quanto ao } \\
\text { tempo de batida }\end{array}$ & $\begin{array}{l}\text { Fixação de cartazes e } \\
\text { treinamento }\end{array}$ & 5,00 & 50,00 & 634,13 & $-562,75$ & $+557,75$ & 0,1 \\
\hline \multicolumn{2}{|c|}{ Total } & 160,00 & 579,5 & $7.349,51$ & $-6.522,31$ & $6.362,31$ & - \\
\hline
\end{tabular}

Tabela 3. Indicadores utilizados para a produção do pão francês (apenas das medidas implementadas e monitoradas) na empresa 1.

\begin{tabular}{lccc}
\multicolumn{1}{c}{ Indicadores } & Unidade & $\begin{array}{c}\text { Situação } \\
\text { encontrada }\end{array}$ & $\begin{array}{c}\text { Situação } \\
\text { modificada }\end{array}$ \\
\hline 1 - Quantidade de água por massa de farinha processada & $\%$ & 47 & 52 \\
2 - Geração de resíduos de embalagens por mês & $\mathrm{kg} / \mathrm{mês}$ & 25,3 & 16,5 \\
3 - Tempo de manipulação por dia & minutos/dia & 15 & 4 \\
4 - Custo por quilo de massa & $\mathrm{R} \$$ & 1,52 & 1,46 \\
$\begin{array}{l}5 \text { - Consumo de energia elétrica - batedeira e cilindro (produção de um } \\
\text { dia de pão francês) }\end{array}$ & $\mathrm{kWh}$ & 3,46 & 2,69 \\
\hline
\end{tabular}




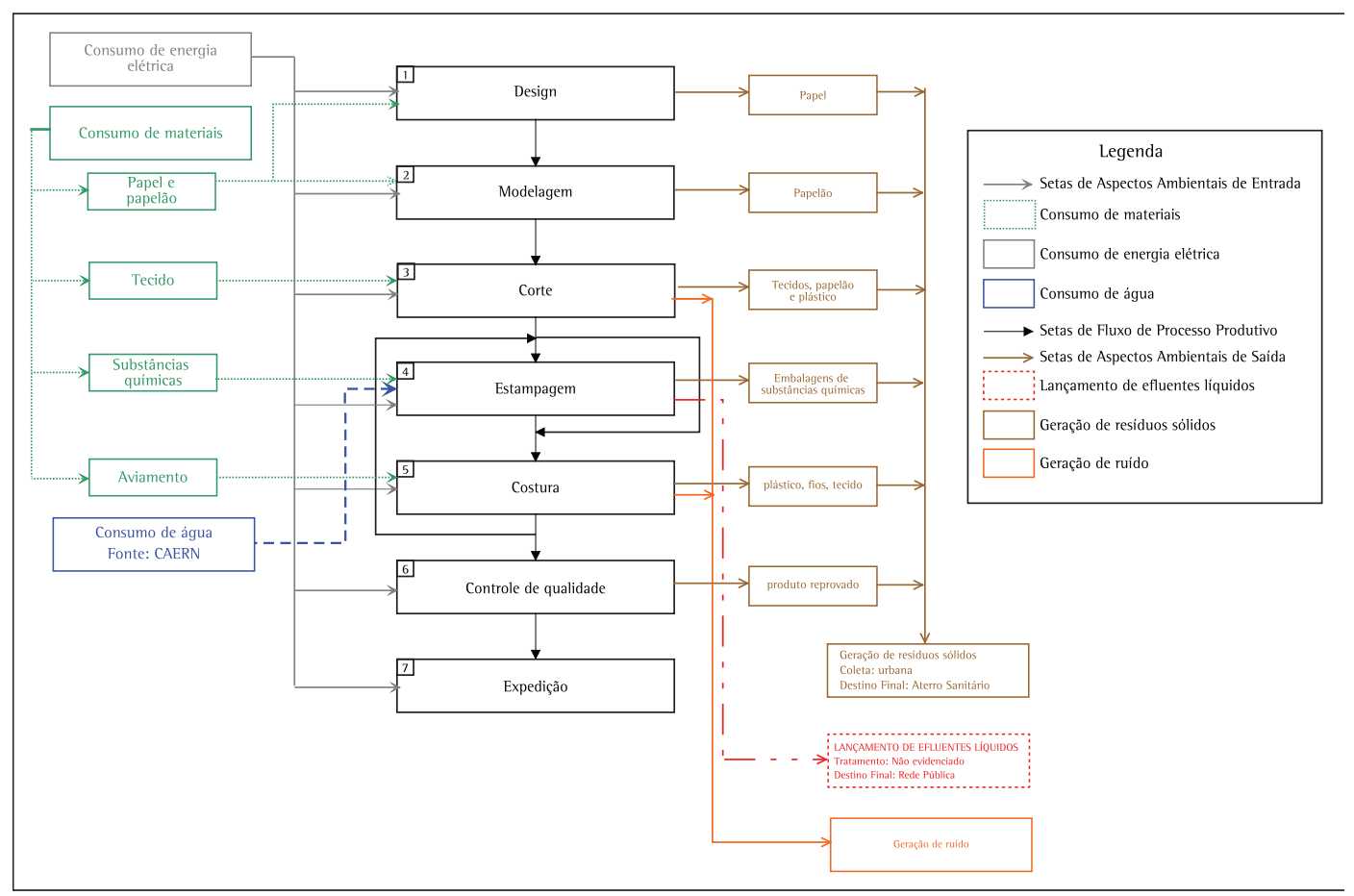

Figura 4. Fluxograma qualitativo da empresa 2.

do corte do tecido, de acordo com o formato e a quantidade dos componentes, seguido da costura e/ou estampagem. Finalizando, tem-se controle de qualidade, do qual, quando identificados pequenos erros de costura, furos na malha ou manchas, os produtos voltam para efetuar as correções possíveis, e expedição,.

A seguir, serão comentados alguns pontos críticos identificados. A empresa não utilizava nenhum programa para efetuar um plano de corte, fazendo este de forma intuitiva. 0 enquadramento dos moldes no tecido a ser cortado era efetuado de forma aleatória, de acordo com a conveniência do operador, acarretando significativo desperdício de material. Desta forma, foi investigado como era efetuado o consumo de tecido de algodão e poliéster, os quais representavam 70\% do consumo total de tecido.

Pelos resultados, foi constatado um desperdício médio de mais de 20\% no consumo desses tecidos. Eram desperdiçados cerca de $40 \mathrm{~kg}$ de tecido por dia, ou seja, mais de 10 t/ano. Em valores monetários, a perda mensal chegava a $\mathrm{R} \$ 18.030,54$ (anualmente, $\mathrm{R} \$ 228.672,38)$. Esses materiais eram queimados no quintal da empresa ou destinados ao aterro sanitário.

No setor de limpeza das placas de estampagem foram constatados desperdícios no uso da água. A primeira fonte de desperdício era uma torneira quebrada, que ocasionava um vazamento de $4 \mathrm{mil} \mathrm{L/mês.} \mathrm{A} \mathrm{segunda} \mathrm{fonte} \mathrm{estava} \mathrm{associada} \mathrm{à}$ forma com que as placas de estampagem eram lavadas, já que não havia um sistema para otimizar o uso, por exemplo, aumentando a pressão da água. Essa situação acarretava em um maior consumo e geração de efluentes líquidos. 0 consumo de água do setor foi estimado em $2.300 \mathrm{~L} /$ dia, considerando a vazão da torneira e o tempo de funcionamento da mesma para o processo de lavagem de cada placa e ainda descontando o volume do vazamento (134 L/dia).

Também foi constatado um desperdício no consumo de energia elétrica no processo de secagem da estampa. Esse processo era efetuado através de placas metálicas munidas de uma resistência elétrica (potência de 0,450 kW) denominadas "berço". Os berços estavam instalados em conjuntos de 6 ou 12 unidades por mesa (Figura 5). Entretanto, o controle de fornecimento de energia no processo não era efetuado de forma individualizada, ou seja, quando uma mesa era acionada, todos os berços eram ligados. Averiguando o uso das mesas através de uma planilha instalada ao lado da chave, que informava os horários em que a mesa era ligada e desligada, e a quantidade de berços utilizados, foi constatado uma eficiência de 70\%, além do tempo médio de uso de 2,5 horas/dia e consumo energético total de $60,75 \mathrm{kWh} /$ dia. Esse desperdício representava uma perda de 400,95 kWh/mês.

Assim, frente aos resultados do diagnóstico operacional e ambiental, as oportunidades vislumbradas serão comentadas a seguir. Em relação ao corte, inicialmente foi sugerida a compra de um software 
de elaboração de plano de corte e DE um plotter para impressão (investimento de R\$90.172,00), sugestão descartada pelo empresário devido ao investimento ter um valor significativo.

Assim, a segunda proposta partiu para o nível housekeeping, através de um treinamento (noção de áreas, figuras geométricas e aproveitamento de espaço) para máximo enquadramento dos moldes. Ainda gerando retalhos, esses passariam por um procedimento de classificação para reaproveitamento interno (retalhos com área superior a $600 \mathrm{~cm}^{2}$ seriam destinados à fabricação de produtos infantis, critério definido pelo responsável pelo corte e ecotime). Caso não fosse possível, seriam destinados à venda a empresas de artesanato, a um preço de $\mathrm{R} \$ 0,70 / \mathrm{kg}$ (confecção de fuxicos - colchas para cama, toalhas de mesa, travesseiros e tapetes) (Figura 6).

Com a implementação da segunda alternativa, foi observado um aumento da eficiência do corte da ordem de 5\% e redução da geração de resíduos. Com o sistema de classificação, foi constatado que o material classificado para reaproveitamento interno representava 55\% dos resíduos gerados pelo corte e que seria possível a arrecadação de uma receita

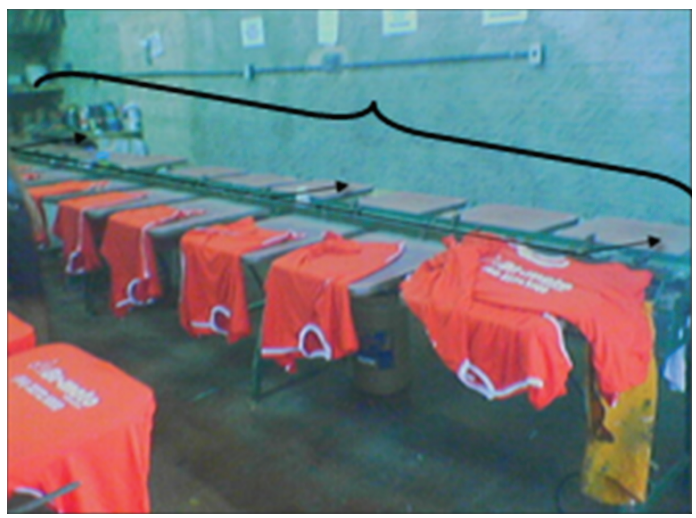

Figura 5. Desperdício de energia elétrica na utilização dos berços na empresa 2 . mensal de $\mathrm{R} \$ 212,98$ com a venda do material para reciclagem externa.

$\mathrm{Na}$ estamparia, as soluções propostas foram: aquisição e substituição da torneira (housekeeping); aquisição e instalação de um equipamento de lavagem pressurizado (modificação tecnológica) e instalação de interruptores nos berços (modificação tecnológica).

A substituição da torneira levou a uma economia de mais de 48 mil litros de água por ano, a um baixo custo (R\$ 10,00).

Já com a instalação do lavador pressurizado foi estimada uma economia de $35.420 \mathrm{~L} /$ mês, com um custo operacional do equipamento estimado em R\$ 35,97/mês, levando em consideração a potência elétrica de 1,4 kW (fornecida pelo fabricante); o tempo médio de uso de 3 horas por dia; o custo do kWh (especificado no consumo ativo fornecido pela conta de energia do mês de maio de 2007); o consumo de $2.300 \mathrm{~L} /$ dia pelo setor e uma economia de 70\% do consumo de água (dado fornecido pelo fabricante). A economia mensal oriunda da implementação desta alternativa foi de $\mathrm{R} \$ 75,25$, com uma rentabilidade de $\mathrm{R} \$$ 596,94 (Tabela 4).

Finalmente, em relação à questão do consumo energético nos berços, foi proposta a instalação de um sistema de chaves de controle (interruptores). Para as mesas com 6 berços foi proposta a instalação de dois interruptores e para a mesa com 12 berços, de 4. Estima-se um aumento da eficiência no uso dos berços na ordem de 98\%. Para tanto, o investimento necessário na aquisição e instalação dos interruptores seria de $\mathrm{R} \$ 250,00$. Por decisão do empresário, essa proposta ficou como uma ação para o plano de continuidade.

Nas Tabelas 4 e 5 serão apresentados, respectivamente, o estudo de viabilidade e os indicadores da situação antes e com as modificações. Pelos resultados é possível observar um aumento na eficiência do uso de recursos naturais - água $(70 \%)$ e tecido (5\%) - e uma diminuição da geração

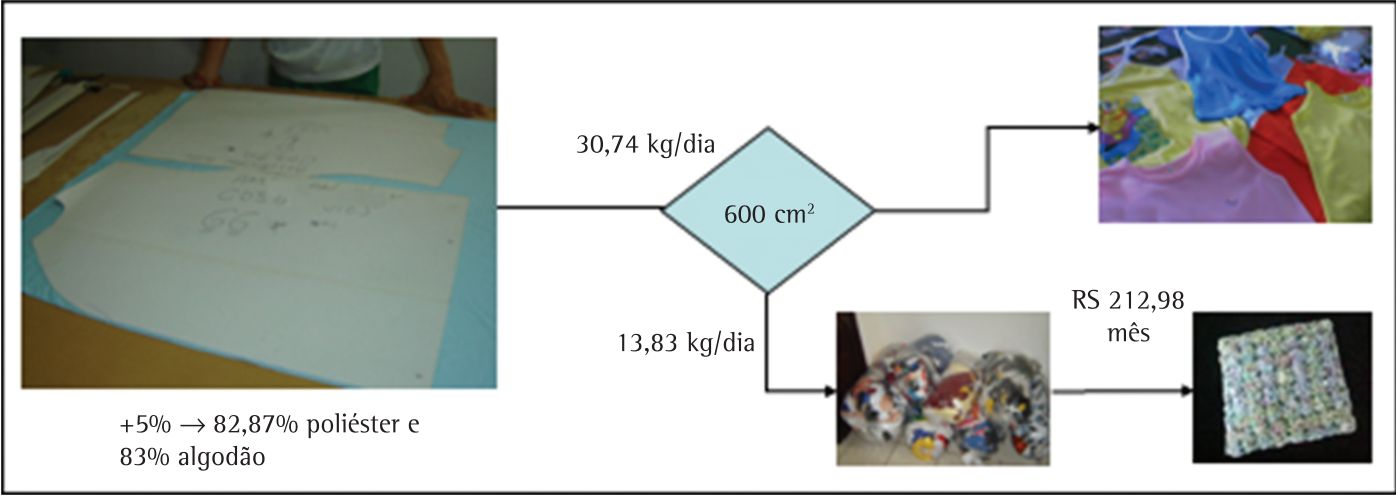

Figura 6. Sistema de produção mais limpa implementando na empresa 2, contemplando redução na fonte, reciclagem interna e externa. 
Tabela 4. Análise de viabilidade das oportunidades na empresa 2.

\begin{tabular}{|c|c|c|c|c|c|c|c|}
\hline \multirow[b]{2}{*}{ Aspecto crítico } & \multirow[b]{2}{*}{ Solução } & \multirow{2}{*}{$\begin{array}{l}\text { Investimento } \\
\text { (R\$) }\end{array}$} & \multicolumn{2}{|c|}{$\begin{array}{c}\text { Receita } \\
\text { gerada/projetada }\end{array}$} & \multicolumn{3}{|c|}{ Análise financeira } \\
\hline & & & Mês (R\$) & $\begin{array}{l}\text { Ano (VF) } \\
\text { (R\$) }\end{array}$ & $\begin{array}{c}\text { VPL } \\
\text { encontrada } \\
(\mathrm{R} \$)\end{array}$ & $\begin{array}{l}\text { VPL } \\
\text { proposta } \\
\text { (R\$) }\end{array}$ & $\begin{array}{c}\text { Pay- } \\
\text { back } \\
\text { (meses) }\end{array}$ \\
\hline $\begin{array}{l}\text { Procedimento incorreto } \\
\text { do corte do tecido tipo } \\
\text { poliéster e algodão }\end{array}$ & $\begin{array}{l}\text { Treinamento para } \\
\text { maximização da alocação } \\
\text { de moldes nos tecidos }\end{array}$ & 300,00 & $4.296,73$ & $54.493,29$ & $-228.672,38$ & $+13.521,48$ & $10^{-5}$ \\
\hline $\begin{array}{l}\text { Desperdício de } \\
\text { água - torneira vazando }\end{array}$ & $\begin{array}{l}\text { Aquisição e troca da } \\
\text { torneira quebrada }\end{array}$ & 10,00 & 12,58 & 159,55 & $-141,59$ & $+131,59$ & 0,8 \\
\hline $\begin{array}{l}\text { Desperdício de } \\
\text { água - procedimento } \\
\text { inadequado de lavagem } \\
\text { das placas }\end{array}$ & $\begin{array}{l}\text { Aquisição e instalação de } \\
\text { lavador com pressão }\end{array}$ & 250,00 & 75,25 & 954,36 & $-1.251,79$ & $+596,94$ & 3,4 \\
\hline $\begin{array}{l}\text { Desperdício no consumo } \\
\text { de energia elétrica nos } \\
\text { berços }\end{array}$ & $\begin{array}{l}\text { Instalação de } \\
\text { interruptores }\end{array}$ & 250,00 & 155,97 & $1.978,09$ & $-1.755,45$ & $+1.505,45$ & 1,6 \\
\hline \multicolumn{2}{|c|}{ Total } & 810,00 & $4.540,53$ & $57.585,29$ & $-231.821,21$ & $+15.755,46$ & - \\
\hline
\end{tabular}

Tabela 5. Indicadores utilizados na empresa 2 (apenas das medidas implementadas e monitoradas).

\begin{tabular}{|c|c|c|c|}
\hline Indicadores & Unidade & $\begin{array}{c}\text { Situação } \\
\text { encontrada }\end{array}$ & $\begin{array}{c}\text { Situação } \\
\text { modificada }\end{array}$ \\
\hline 1 - Eficiência média do uso de poliéster e algodão & $\%$ & 77,89 & 82,89 \\
\hline 2 - Quantidade de resíduos sólidos gerados e dispostos em aterro (tecido) & $\mathrm{kg}$ & 873,84 & 0,00 \\
\hline 3 - Consumo de água nas placas de estampagem & $\mathrm{m}^{3} / \mathrm{mês}$ & 53,55 & 15,18 \\
\hline
\end{tabular}

de efluentes $(71,23 \%)$. Em relação aos aspectos econômicos, destaca-se uma economia anual de $\mathrm{R} \$ 55.946,96$, tornando a empresa mais produtiva e com tendência de se tornar mais competitiva.

Quanto ao plano de continuidade, as medidas traçadas foram: instalar uma estação de tratamento de efluentes líquidos industriais com eficiência para remoção de substâncias químicas - para tanto faz-se necessária a contratação de um profissional habilitado; compra de equipamentos de proteção individual; contratação de uma consultoria para realização de ginástica laboral com os funcionários, principalmente as costureiras; aquisição do software e hardware para elaboração de planos de corte; efetuar reuniões quinzenais com o ecotime e efetuar palestras mensais dentro das temáticas da qualidade, segurança do trabalho e meio ambiente.

Efetuada a visita, seis meses depois da finalização do programa, observou-se que as medidas implementadas continuavam dentro do que foi traçado e que não houve avanço nas medidas contidas no plano de continuidade, exceto nas reuniões do ecotime (que passaram a ser mensais, devido ao aumento das demandas) e na entrega dos EPls.

\subsubsection{Empresa 3}

0 primeiro passo do diagnóstico operacional e ambiental na empresa 3 foi identificar todos os setores geradores de resíduos e de forma qualitativa identificar quais eram os resíduos gerados, além de entender qual o fluxo contemplado desde a geração até a disposição final. Observou-se, assim, que os resíduos sólidos gerados em cada setor eram acondicionados em coletores não padronizados, não havendo qualquer tipo de segregação e/ou redução na fonte. Quando os coletores estavam cheios, eram esvaziados e tinham o seu conteúdo despejado na caçamba pelos funcionários encarregados da limpeza. A empresa armazenava seus resíduos em caçambas alocadas em uma área calçada e a céu aberto, o que ocasionava sério risco de contaminação do solo em dias de chuva.

A Tabela 6 apresenta a caracterização dos resíduos gerados. Pelos resultados, nota-se uma geração de 2,05 t de resíduos por mês, sendo que 45,66\% eram resíduos recicláveis (papel, papelão e metal), equivalentes a $939 \mathrm{~kg} / \mathrm{mês}$. Os demais eram rejeitos, materiais sem possibilidade de reaproveitamento ou reciclagem, como trapos, películas para automóveis, filtros de ar, copos descartáveis, embalagens de alimentos, entre outros.

0 setor que mais contribuía para a geração era a oficina mecânica, com 35,89\%, isto é, o equivalente a $738 \mathrm{~kg}$ por mês, seguido da funilaria e da administração (Tabela 7). Destaca-se que a oficina mecânica também era o setor que mais contribuía com a geração de plástico e metal na empresa, 50,60\% e $88,87 \%$, respectivamente. 1sto se justifica pelo fato de haver muita substituição de peças e partes integrantes do veículo. Já o setor de peças e assessórios era o que mais contribuía para a geração de papel e papelão, 
com 25,29\%. Isto ocorre devido ao setor fornecer à oficina mecânica e à funilaria, peças e acessórios retendo as embalagens no setor de origem. A funilaria, por sua vez, era o setor que mais contribuía para a geração de rejeitos, ou seja, 44,47\%.

Contudo, observa-se a potencialidade da empresa em promover a reciclagem externa, principalmente devido à elevada geração de resíduos, ou seja, mais de $11 \mathrm{t} / \mathrm{ano}$. Desa forma, o indicador utilizado para esta abordagem será a quantidade de resíduos destinados à reciclagem externa.

Assim, frente ao resultado da caracterização dos resíduos, a seguir, será apresentado o estudo de viabilidade da oportunidade de segregação na fonte geradora e destinação dos resíduos recicláveis para reciclagem externa.

Frente à tipologia de resíduos de cada setor e à massa e ao volume gerados, foram levantados os tipos de acondicionadores para cada setor. Visando uma padronização, foram adotadas as seguintes cores: azul (papel e papelão); vermelho (plásticos), amarelo (metal), cinza (rejeito) e laranja (embalagens plásticas contaminadas com óleo).

0 projeto contemplou 81 acondicionadores de 14 , 22 e $97 \mathrm{~L}$ de polipropileno, além de tonéis metálicos de $190 \mathrm{~L}$ (reaproveitamento das embalagens de óleo comprado, sendo limpo, descontaminado e pintado conforme a necessidade) e um kit de coleta seletiva contendo os acondicionadores padrão e suporte. Também foi dimensionada e projetada uma

Tabela 6. Caracterização dos resíduos sólidos gerados pela empresa 3.

\begin{tabular}{lrrr}
\hline \multirow{2}{*}{ Residuos sólidos gerados } & \multicolumn{3}{c}{ Massa (kg) } \\
\cline { 2 - 4 } & \multicolumn{1}{c}{ Mês } & \multicolumn{1}{c}{ Ano } & \multicolumn{1}{c}{$\%$} \\
\hline Papel/papelão & 508,8 & $6.105,6$ & 24,74 \\
Plástico & 364,6 & $4.375,2$ & 17,73 \\
Metal & 65,6 & 787,2 & 3,19 \\
Rejeito & $1.117,5$ & 13.410 & 54,34 \\
Total & $2.056,5$ & 24.678 & 100,00 \\
\hline
\end{tabular}

Tabela 7. Quantificação dos resíduos sólidos gerados por setor da empresa 3

\begin{tabular}{ccccc}
\hline \multirow{4}{*}{ Setores } & \multicolumn{4}{c}{ Resíduos gerados por setor } \\
\cline { 2 - 5 } & $\begin{array}{c}\text { Papel/ } \\
\text { papelão } \\
(\mathrm{Kg})\end{array}$ & $\begin{array}{c}\text { Plástico } \\
(\mathrm{Kg})\end{array}$ & $\begin{array}{c}\text { Metal } \\
(\mathrm{Kg})\end{array}$ & $\begin{array}{c}\text { Regeito } \\
(\mathrm{Kg})\end{array}$ \\
\hline $\begin{array}{c}\text { Administração } \\
\text { Funilaria }\end{array}$ & $\begin{array}{c}100,1 \\
21,1\end{array}$ & 20,6 & - & 95,7 \\
$\begin{array}{c}\text { Oficina } \\
\text { mecânica }\end{array}$ & 123,2 & 184,8 & - & 485,80 \\
$\begin{array}{c}\text { Peças/ } \\
\text { acessórios }\end{array}$ & 128,7 & 49,3 & - & 17,6 \\
$\begin{array}{c}\text { Posto de } \\
\text { lavagem } \\
\text { Vendas }\end{array}$ & 19,1 & 52,1 & - & 74,8 \\
\hline
\end{tabular}

área de armazenamento temporário, para evitar a depreciação do material separado na fonte geradora, com capacidade de armazenamento de $9.700 \mathrm{~L}$ de resíduos, dividida em quatro baias (papel e papelão, plásticos, metal e embalagens plásticas de óleo).

Quanto à potencialidade de receitas oriundas das vendas dos resíduos recicláveis a uma empresa devidamente licenciada, o projeto apresentou receita mensal de R\$174,03, conforme Tabela 8.

Desta forma, a análise da viabilidade econômica foi efetuada considerando o custo de compra dos acondicionadores de resíduos ( $\mathrm{R} \$ 1.702,20)$, o custo de construção da área de armazenamento ( $R$ \$ 1.500) e o custo de capacitação dos funcionários ( $R$ \$ 1.000), e ainda o custo mensal de $R \$ 1.260$, referentes à disposição final dos resíduos e a possibilidade de se reduzir em 50\% este valor com a implementação do projeto. Pelos resultados apresentados na Tabela 9, considerando o horizonte de um ano, o custo da solução encontrada para descarte dos resíduos no aterro sanitário seria de $R$ \$ 14.181,40. Com a implantação do projeto, o custo anual com o gerenciamento de resíduos cairia para $R \$ 9.334,18$, isto é, uma redução de $34 \%$, e o investimento seria pago em 2-3 anos.

Com o intuito de tornar os funcionários da empresa sensíveis às questões ambientais e capacitados a agir de acordo com os procedimentos da segregação na fonte, uma série de ações de educação ambiental foram realizadas, como treinamento com carga horária de 10 horas, abordando a temática em questão e os procedimentos a serem adotados na concessionária; fixação de diversos cartazes em pontos estratégicos da empresa; realização de peças teatrais; entrega de mudas de espécies nativas para os funcionários da empresa, a fim de despertá-los para a questão da reciclagem do papel; distribuição de sementes de plantas e de cartilhas para os clientes.

Destaca-se que após a implementação dessas ações e a instalação da estrutura planejada, a comercialização dos recicláveis aumentou consideravelmente. De acordo com o monitoramento efetuado de outubro de 2007 até dezembro de 2008 (Figura 7), foram destinados para a reciclagem externa mais de $18 \mathrm{t}$ de resíduos, compostas de 11,3 t de papel e papelão, 2,4 t de

Tabela 8. Receita projetada com a comercialização de resíduos recicláveis.

\begin{tabular}{lccc}
\hline $\begin{array}{l}\text { Resíduos } \\
\text { recicláveis }\end{array}$ & $\begin{array}{c}\text { Quantidade } \\
\text { (kg/mês) }\end{array}$ & $\begin{array}{c}\text { Valor comercial* } \\
\text { (R\$) }\end{array}$ & $\begin{array}{c}\text { Receita projetada } \\
\text { (R\$/mês) }\end{array}$ \\
\hline Papel/papelão & 508,8 & 0,15 & 76,32 \\
Plásticos & 364,6 & 0,25 & 91,15 \\
Metais & 65,6 & 0,10 & 6,56 \\
Total & & 174,03 \\
\hline $\begin{array}{l}\text { *Preços estabelecidos com a empresa selecionada para a compra dos recicláveis } \\
\text { (outubro de 2007). }\end{array}$
\end{tabular}


Tabela 9. Análise financeira da implementação da oportunidade de reciclagem externa na empresa 3.

\begin{tabular}{cccccc}
\hline & \multicolumn{2}{c}{ Receita projetada } & \multicolumn{3}{c}{ Análise financeira } \\
\cline { 2 - 6 } Investimento (R\$) & Mês (R\$) & Ano (VF) (R\$) & $\begin{array}{c}\text { VPL } \\
\text { encontrada (R\$) }\end{array}$ & $\begin{array}{c}\text { VPL } \\
\text { proposta (R\$) }\end{array}$ & Pay-back (meses) \\
\hline $4.202,20$ & 174,03 & $2.207,14$ & $-14.181,40$ & $-9.334,18$ & 27,8 \\
\hline
\end{tabular}

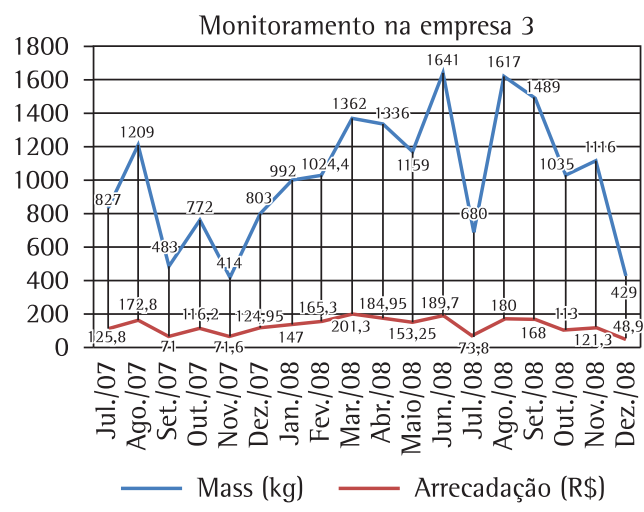

Figura 7. Monitoramento do gerenciamento de resíduos sólidos da empresa 3.

plástico e 4,6 t de metal. No primeiro ano, a média de materiais retornados para a cadeia produtiva foi de 751,33 kg/mês, já em 2008 passou a 1.156,70 kg/mês, estando inclusive acima do previsto na fase de diagnóstico. Esse aumento se atribuiu à melhor participação dos atores envolvidos e à instalação da estrutura necessária para conservação do material. Em relação às receitas geradas, foi observado um crescimento proporcional, permitindo à empresa obter um montante de $\mathrm{R} \$ 2.428,85$.

Em relação ao custo da disposição de rejeitos, este caiu à metade com a destinação do material para reciclagem. 0 rejeito passou a ser destinado ao aterro por uma empresa licenciada. E os materiais reciclados passaram a ser reciclados por empresas recicladoras do RN.

No tocante ao plano de continuidade, este foi relacionado às inspeções e monitoramento pelo ecotime da destinação dos resíduos para reciclagem externa, na continuidade dos programas de educação ambiental e no levantamento de oportunidades de redução na fonte geradora. Destaca-se ainda que foram traçadas medidas com relação a outros dois aspectos potencialmente significativos: efetuar um estudo sobre a potencialidade de reuso de água de chuva para a lavagem de carros e outros fins e efetuar um estudo sobre eficiência energética na empresa como um todo.

Contudo, na empresa 3 foi observada uma redução significativa na destinação dos resíduos ao aterro sanitário, além da redução do custo da disposição final, tornando o projeto viável financeiramente. No processo de implantação foi necessária uma participação mais ativa de todos os funcionários, induzida por ações de educação ambiental. 0 desafio da correta segregação na fonte geradora foi indutor de um processo de mudança cultural na empresa frente aos cuidados com o meio ambiente, promovendo também uma maior integração entre setores, satisfação dos funcionários e envolvimento de clientes.

\section{Considerações finais}

0 presente estudo buscou avaliar a PmL como uma ferramenta da sustentabilidade empresarial, através de uma série de estudos de múltiplos casos em empresas do RN. Assim, o estudo analisou os aspectos ambientais dos setores efetivamente geradores de desperdícios e com base em uma avaliação técnica e financeira foi possível evidenciar e apresentar elementos de discussão favoráveis à incorporação da variável ambiental no seu processo de gestão corporativa.

Na empresa de panificação, com o consumo de água fora das especificações técnicas, 19.800 pães do tipo francês não eram fabricados anualmente. Esse desperdício foi corrigido com a utilização de um balde com demarcações para uso do volume correto de água. Também foram vislumbradas oportunidades de melhoria no uso energético por meio do estabelecimento de tempos-padrão (economia de $277 \mathrm{kWh} / \mathrm{ano}$ ), substituição de matérias-primas, acarretando na diminuição do tempo de manipulação, geração de resíduos e redução da pressão sobre os funcionários. Dessa forma, foi observada uma economia de $R \$ 6.522,31$ por ano apenas na fabricação do pão francês.

$\mathrm{Na}$ empresa 2 foi evidenciada uma perda de 10 t/ano em tecido de algodão e poliéster devido a falhas no sistema de corte. A solução desse aspecto crítico ocorreu com a otimização do corte e reciclagem interna e externa. Também foi vislumbrada a otimização do uso de água. Monetariamente, as medidas implementadas geraram uma economia anual de $\mathrm{R} \$$ 55.946,96.

Por fim, na concessionária de veículos foi averiguada uma geração de $2 \mathrm{t}$ de resíduos por mês, os quais eram dispostos no aterro sanitário, a um custo mensal de $\mathrm{R} \$ 1 \cdot 260,00$. Foi observado também que $45,66 \%$ desses resíduos eram recicláveis. Dessa 
forma, o projeto focou a segregação dos resíduos na fonte e o envio do material para reciclagem externa, acarretando em um retorno de mais de $18 \mathrm{t}$ de resíduos para a cadeia produtiva.

De forma geral, nas empresas estudadas foi constatado que a geração de desperdícios era potencializada pela falta de conhecimento por parte do empresário/diretoria sobre os aspectos e impactos ambientais de suas atividades, pela falta de uma visão da necessidade do uso racional dos recursos e pela falta de uma maior cobrança dos funcionários. Assim, foi necessária uma maior conscientização ambiental em todos os níveis organizacionais das empresas estudadas.

Também foi averiguado que quando houve necessidade de aporte de recursos financeiros mais significativos para implementação de oportunidades de melhoria, houve resistência por parte da gerência/administração, mesmo com a apresentação das vantagens de ordem econômica e ambiental. Nessa conjuntura percebe-se que mesmo com o engajamento do ecotime e a cobrança dos funcionários, além da apresentação de estudos técnicos consolidados e fortemente respaldados financeiramente, se não existirem vontade e comprometimento do empresário/direção, ou mesmo uma cobrança externa (e.g. governo, clientes, investidores, parceiros comerciais, fornecedores), a implementação do projeto bem como a sua continuidade podem ficar comprometidas.

Por outro lado, acredita-se que o sucesso dos casos implementados e mantidos esteja associado à simplicidade das oportunidades implementadas, que trouxeram resultados expressivos para empresa, motivando o empresário a cobrar atitudes por parte do ecotime e funcionários na continuidade e melhoria das ações.

Contudo, nota-se que a PmL pode ser aplicada sem restrições tanto em empresas industriais quanto prestadoras de serviço, trazendo benefícios econômicos (redução de custos operacionais), ambientais (otimização do uso de recursos e diminuição dos desperdícios) e sociais (ganho de uma consciência ambiental, busca de redução dos riscos aos funcionários), com retorno de investimento a curto e médio prazos. Esses fatores podem evidenciar que a PmL auxiliou a empresa a incorporar uma postura social e ambiental, direcionando-a a uma melhor posição no mercado.

Assim, retomando o conceito de PmL - "aplicação contínua de uma estratégia ambiental preventiva e integrada a processos, produtos e serviços para aumentar a eficiência global e reduzir riscos aos seres humanos e ao meio ambiente" (UNITED..., 2007) - e relacionando-o com as características da sustentabilidade empresarial, nota-se que essa ferramenta, além de posicionar as empresas em um cenário competitivo, previne de forma continuada a geração de desperdício e reduz os riscos das operações sobre os funcionários, comunidade e meio ambiente, contemplando as vertentes ambientais e sociais da sustentabilidade.

Entretanto, faz-se necessário maior transparência da alta administração no comprometimento com a continuidade das ações para, diante disto, melhor enquadrar a PmL como uma ferramenta da sustentabilidade.

\section{Referências}

ALMEIDA, C. M. V. B.; GIANNETTI, B. F. Ecologia industrial: Conceitos ferramentas e aplicações. São Paulo: Edgard Blücher, 2006. $109 \mathrm{p}$.

ALMEIDA, F. O bom negócio da sustentabilidade. Rio de Janeiro: Nova Fronteira, 2002. 208 p.

ARAÚJO, A. F. A aplicação da metodologia de produção mais limpa: estudo em uma empresa do setor de construção civil. 2002. 120 f. Dissertação (Mestrado em Engenharia de Produção)-Universidade Federal de Santa Catarina, Florianópolis, 2002

CAMPOS, A. L. 0.; RABELO, T. S.; SANTOS, R. 0. Produção mais limpa na indústria de petróleo: o caso da água produzida no campo de Carmópolis-SE. In: CONGRESSO DE ENGENHARIA SANITÁRIA E AMBIENTAL, 23., 2005, Campo Grande. Anais... Campo Grande: ABES, 2005. p. $1-7$.

CENTRE FOR APPLIED POLICY RESEARCH - CAP. Definitions of sustainability. Forschungsgruppe Zukunftsfragen Research Group on the Global Future, 2003. Disponivel em: <http://www.cap-lmu.de/fgz/portals/sustainability/ definitions.php> Acesso em: 10 fev. 2008

CENTRO NACIONAL DE TECNOLOGIAS LIMPAS - CNTL. Meio ambiente e a pequena e microempresa: módulo 1 - Curso de Formação de Consultores em Produção Mais Limpa. Porto Alegre: CNTL, 2003. 73 p.

CICCOZZI, E.; CHECKENYA, R.; RODRIGUEZ, A.V. Recent experiences and challenges in promoting cleaner production investments in developing countries. Journal of Cleaner Production, v. 11, p. 629-638, 2003. http:// dx.doi.org/10.1016/S0959-6526(02)00106-3

CORAL, E. Modelo de planejamento estratégico para a sustentabilidade empresarial. 2002. 282 f. Tese (Doutorado em Engenharia de Produção)-Universidade Federal de Santa Catarina, Florianópolis, 2002.

CRAMER, J.; STEVELS, A.The unpredictable process of implementing eco-efficiency strategies. In: CHARTER, M.; TISCHNER, U. (Orgs.). Sustainable solutions: developing products and services for the future. Sheffield: Greenleaf Publishing, 2001. $469 \mathrm{p}$.

GLAVIC, P.; LUKMAN, R. Review of sustainability terms and their definitions. Journal of Cleaner Production, v. 15, p. 1875-1885, 2007. http://dx.doi.org/10.1016/j. jclepro.2006.12.006

HART, S. L.; MILSTEIN, M. B. Criando valor sustentável. RAE Executivo, v. 3, n. 2, p. 65-79, 2004.

JAPPUR, R. F. A sustentabilidade corporativa frente às diversas formações de cadeias produtivas segundo a percepção de especialistas. 2004. 161 f. Dissertação (Mestrado em 
Engenharia de Produção)-Universidade Federal de Santa Catarina, Florianópolis, 2004.

KUHNDT, M. Sustainable business development. In: SElLER, H. J. D.; LIEDTKE, C.; WEIZSÄCKER, E. U. (Orgs.). Eco-efficiency and beyond: toward the sustainable enterprise. Sheffield: Greenleaf Publishing, 2004. 248 p.

LUKEN, R. A.; NAVRATIL, J. A programmatic review of UNIDO/UNEP national cleaner production centers. Journal of Cleaner Production, v. 12, p. 195-205, 2007. http://dx.doi.org/10.1016/S0959-6526(03)00102-1

MASERA, D. et al. A produção mais limpa e o consumo sustentável na América Latina e Caribe. Lomas de Virreyes: PNUMA/CETESB. 2004. 112 p.

PEREIRA, C. L. F. Produção mais Limpa como um instrumento de gestão ambiental: um Estudo de Caso em uma Indústria de Cerâmica Esmaltada. 2003. 126 f. Dissertação (Mestrado em Gestão e Políticas Ambientais)-Universidade Federal do Pernambuco, Recife, 2003.

PHILIPPINE COUNCIL FOR SUSTAINABLE DEVELOPMENT - PCSD. What is sustainable development. Disponivel em: <http://pcsd.neda.gov.ph/susdev.htm>. Acesso em: 15 fev. 2008

ROBLES JUNIOR, A.; BONELI, V. V. Gestão da qualidade e do meio ambiente: enfoque econômico, financeiro e patrimonial. São Paulo: Atlas, 2006. 112 p.

SEBRAE. Metodologia de produção mais Limpa e barreiras. Rio de Janeiro: SEBRAE/CEBDS, 2005. 89 p.

SEBRAE-RN. Empresas piloto do Pmaisl: apresentação resultados. Natal: SEBRAE-RN/Núcleo Potiguar de Econegócios, 2005.

SHI, H.; PENG, S. Z.; ZHONG, P. Barriers to the implementation of cleaner production in Chinese SMEs: government, industry and expert stakeholders' perspectives. Journal of Cleaner Production, p. 1-11, 2007.

SILVA, E. L.; MENEZES, E. M. Metodologia da pesquisa e elaboração de dissertação. 2. ed. Florianópolis: Laboratório de Ensino a Distância da UFSC, 2001. 120 p.

SILVA, G. C. S.; MEDEIROS, D. D. Metodologia de Checkland aplicada à implementação da Produção mais Limpa em Serviços. Gestão e Produção, v. 13, n. 3, p. 411-422, 2006.

STONE, L. Limitations of cleaner production programmes as organizational change agents. 1. Achieving commitment and on-going improvement. Journal of Cleaner Production, v. 14, p. 1-14, 2006. http://dx.doi. org/10.1016/j.jclepro.2004.12.008

UNITED NATIONS - UN.Un Documents Cooperation Circles Gathering. A Body Of Global Agreements. 1987. Report of the World Commission on Environment and Development: Our Common Future. Disponível em: <http://www.un-documents.net/ocf-02.htm\#l>Acesso em: 10 jan. 2008

UNITED NATIONS ENVIRONMENTAL PROGRAMME-UNEP. Understanding Cleaner Production: National Cleaner Production Centers. Disponivel em: <http://www. uneptie.org/pc/cp/ncpc/home.htm>. Acesso em: 20 out. 2007.

UNITED NATIONS INDUSTRIAL DEVELOPMENT ORGANIZATION - UNIDO. Manual on the development of cleaner productions policies: approaches and instruments. Viena, 2002. 141 p. Disponível em <www. unido.org>. Acesso em: 02 ago. 2006.

WEIHS, G.; WEISSEL, W. Ecoprofit - profits from cleaner production: project replication guieline. Eitweg: Centre of Environmental Training And Internacional Consulting, 2005. $61 \mathrm{p}$.

\title{
Cleaner production as corporate sustainability tool: a study within companies from Rio Grande do Norte State
}

\begin{abstract}
The purpose of this stydy was to assess the Cleaner Production - CP as a corporate sustainability tool, through a multiple case study in companies from the State of Rio Grande do Norte. To this end, our research methodology approach used the CP methodology from SEBRAE (2005) and applied it to the food industry (Company 1), the textile industry (Company 2) and to a car dealer (Company 3). Results highlighted, among other variables, the specific sustainability focus of any observed cleaner production activity. In company 1, raw material substitution, optimization of water and energy usage were the main foci. In Company 2, the foci were the optimization of fabric usage and technological modification (installation of washing equipment for the printing plates; before that, there was not control of water usage in this process, resulting in increased water consumption and disposal of waste). Company 3 was focused on source segregation and external recycling. However, these results pointed out that environmental, social and economic improvements demand corporate sustainability; and more commitment from executive management is needed to consider $\mathrm{CP}$ as an effective sustainable tool.
\end{abstract}

\section{Keywords}

Corporate sustainability. Cleaner production. Environmental management. Environmental impacts. Waste. 